\title{
Improving the Quality of Digital Images Using the Image Averaging Method
}

\author{
Upa Yuandari \\ Department of Computer Science, STMIK Budi Darma, North Sumatera, Indonesia \\ Email: ${ }^{1}$ upayaundari07@gmail.com
}

\begin{abstract}
Image is a representation (picture), similarity, or imitation of an object. The use of digital images plays an important role as a form of information due to its advantages. Although it is rich in information, not all images have a good visual appearance. This can be due to interference in the form of noise, color intensity that is too contrasting or blurred. Noise itself is a disturbance caused by distorted digital data received by the image data receiver, starting from the movement during shooting by optical devices such as cameras, the use of optical devices that are not in focus, short lighting thereby reducing the number of photos captured by optical devices, or the weather when shooting. Noise can be removed by using the Image Averaging Method.
\end{abstract}

Keywords: Image, Image Averaging Method, Noise.

\section{INTRODUCTION}

Technological sophistication at this time can not be doubted. To get information precisely and practically is not a difficult thing. That happens because we can get information from anywhere. For example information in the form of images (images), text, sound, video and so forth. Merging components is called multimedia.

Remote sensing technology or remote sensing offers convenience in mapping an area. Nowadays remote sensing is very often used because imagery can be made quickly even though it is in an area that is difficult to travel through land so it is very necessary to map disaster areas and the resulting image depicts objects on the surface of the earth with the shape and location of objects that are similar to the actual object . Remote sensing imagery can also describe objects that are in the ground or objects that are on the seabed that reach a certain depth so that the object recognition can be done. With the development of image processing (image processing), humans are competing to produce an attractive image of the image Simple images that exist. In addition, in accordance with the development of time, image processing has increasingly become a necessity by many people, especially in the field of art, filmmaking as a special effect on 3D images.

Image or Image is another term of image, which is visual information. The image has characteristics that are not owned by text data, namely the image is rich with information. Image (image) as one of the multimedia components that play an important role as a form of visual information. The image has characteristics that are not owned by text data, namely the image is rich with information. There is a saying that says "a picture means more than a thousand words" (a picture is more than a thousand words). The point is of course a picture can provide more information than the information presented in the form of words (textual).

Digital image processing (digital image processing) is a field that is developing very rapidly in line with technological advancements. Image Averaging is to improve image quality so that images can be seen more clearly without any strain on the eyes, because important information extracted from the resulting image must be clear so that the best results are obtained. Commonly used logical operations are NOT, OR, and AND operations. Image averaging is done if you have several images with the same picture, but all images have noise. [1]

Although an image is rich in information, but often the image that we have has decreased quality (degradation), for example containing defects or noise (noise), the color is too contrasty, less sharp, blurring, and so on. Of course this kind of image becomes more difficult to interpret because the information conveyed by the image is reduced. In order for images with disturbance to be easily interpreted (both by humans and machines), the images need to be manipulated into other images of better quality using image processing techniques. Often there are many cases about the poor appearance of an image, for example, the image / image is too bright / dark so that the image display is not good. Poor display of an image can occur due to the recording time of the image / image due to poor lighting. Improving image quality by increasing the contrast of gray level is one way to improve the appearance of an image of an underexposed image because it is too dark and to improve an overexposed image that is too bright so that later the image display will be good by using equalization .

\section{THEORY}

\subsection{Image}


The image is a two-dimensional image that is produced from a continuous two-dimensional analog image into a discrete image through a sampling process. Digital imagery can be defined as a function of two variables, $\mathrm{f}(\mathrm{x}, \mathrm{y})$, where $\mathrm{x}$ and $\mathrm{y}$ are spatial coordinates while the values $\mathrm{f}(\mathrm{x}, \mathrm{y})$ are the intensity of the image at these coordinates. The basic technology for creating and displaying colors in digital images is based on research that a color is a combination of three basic colors, namely red, green, and blue (Red, Green, Blue - RGB) [2].

\subsection{Image Averaging Method}

Basically, when shape changes occur, control points are placed between two objects in a correlated location. The deformation algorithm then calculates an "intermediate object", which, if observed sequentially, will change from the initial image to the final image.

Image averaging is done if we have multiple images with the same picture, but all images have noise. Suppose an image with noise $\mathrm{g}(\mathrm{x}, \mathrm{y})$ is formed by adding noise $\mathrm{n}(\mathrm{x}, \mathrm{y})$ to the original image $\mathrm{f}(\mathrm{x}, \mathrm{y})$, $g(x, y)=f(x, y)+n(x, y)$

Assuming that noise from one image is different from other image noise (uncorrelated). For example, if you want to change shape (morphing), between trapezoid and rectangle. First the deformation process is carried out to find the middle shape between the rectangle to the trapezoid. After the two forms are obtained, a cross dissolve process is carried out to combine the colors in the shape. The conclusion is that the deformation process is used to equalize the shapes of the two objects while the cross dissolve process is used to combine the texture of both the image and the purpose of the 3D image. To combine the two colors, the average weight of each primary color is calculated.

$$
\begin{aligned}
& \mathrm{r}=\frac{w_{1} \cdot r_{1}+w_{2} \cdot r_{2}}{w_{2}+w_{2}} \ldots \\
& \mathrm{g}=\frac{w_{1} \cdot g_{1}+w_{2} \cdot g_{2}}{w_{1}+w_{2}} \\
& \mathrm{~b}=\frac{w_{1} \cdot b_{1}+w_{2} \cdot b_{2}}{w_{1}+w_{2}} .
\end{aligned}
$$

With $r_{1} g_{1} b_{1}$ and $r_{2} g_{2} b_{2}$ is the primary color (red, green, blue) for the first pixel and both w1 and w2 are for each pixel. If the first pixel weight is zero, the resulting color is the same as the second pixel. Vice versa, if the weight of the second pixel is zero, the first pixel color will be produced.

Where : $\quad r=$ Specifies the color of the red pixel

$\mathrm{g}=$ Specifies the color of the green pixel

$\mathrm{b}=$ Specifies the color of the blue pixel

$\mathrm{w}=$ Warping Determine the Results of the RBG process

\section{RESULT AND DISCUSSION}

To decompose a whole into components so that they can recognize the signs of each component of the relationship to each other and their respective functions in an integrated whole. Noting, observing something that someone does in the decomposition activities of a whole information system into its component parts with a view to identifying and evaluating problems, opportunities, obstacles that occur and the needs that are expected so that it can be proposed as an improvement.

The image represented in the form of a matrix has a large dimension with rows and columns showing a point in the image and the corresponding value of the matrix element identifying the level at that point. Sharpening $3 \mathrm{D}$ images is based on color recognition using one of the classic operators, the mask mask. The data used in this study are some facial images for testing, where the image used is a grayscale image with an image size of $256 \mathrm{x}$ 256 pixels, then the image will undergo a process to obtain a similarity which is the result image (Image Output).

Input image is an image that has a color intensity ranging from 0 as a minimum value to 255 which is a maximum value. Input images that have a size of $5 \times 5$ pixels are then converted into a matrix $5 \times 5=25$, for each image. To get the gray level value is the sum of the values of $R+G+B$ of each pixel divided by 3 . The formula used is: 
The IJICS (International Journal of Informatics and Computer Science) Vol 4 No 1, March 2020
ISSN 2548-8384 (online) ISSN 2548-8449 (print)

Page 5-11

DOI 10.30865/ijics.v4i1.1982

$$
\text { Greylevel }=\frac{R+G+B}{3}
$$

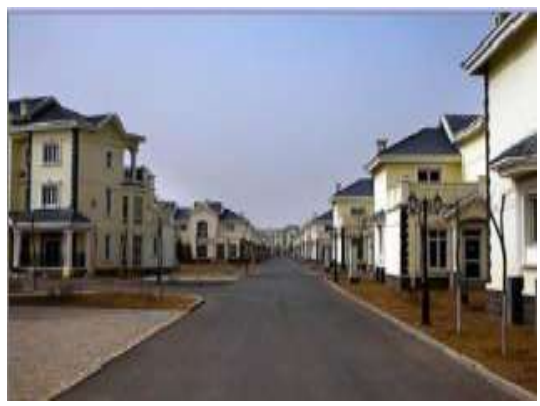

Figure 1. Initial image measuring 317 x 236 pixels

Here is the RGB value of each image pixel in Figure 1. above:

Table 1. RGB Value

\begin{tabular}{cccc}
\hline Pixel & R & G & B \\
\hline 0 & 222 & 220 & 204 \\
1 & 220 & 220 & 212 \\
2 & 237 & 207 & 192 \\
3 & 220 & 220 & 212 \\
4 & 220 & 228 & 220 \\
5 & 220 & 220 & 212 \\
6 & 220 & 228 & 220 \\
7 & 228 & 228 & 218 \\
8 & 220 & 228 & 220 \\
9 & 228 & 230 & 228 \\
10 & 212 & 220 & 212 \\
11 & 220 & 220 & 212 \\
12 & 220 & 220 & 212 \\
13 & 212 & 212 & 196 \\
14 & 220 & 220 & 212 \\
15 & 204 & 204 & 188 \\
16 & 152 & 157 & 152 \\
17 & 190 & 187 & 190 \\
18 & 179 & 181 & 168 \\
19 & 187 & 202 & 197 \\
20 & 187 & 202 & 197 \\
21 & 204 & 204 & 188 \\
22 & 212 & 220 & 212 \\
23 & 212 & 212 & 204 \\
\hline & & &
\end{tabular}

Based on the RGB values in the above table, the greylevel color values are calculated, the following results are obtained:

Tabel 2. Grey Level Value

\begin{tabular}{ccccc}
\hline Pixel & R & G & B & $\begin{array}{c}\text { Grey } \\
\text { Level }\end{array}$ \\
\hline 0 & 222 & 220 & 204 & 215 \\
1 & 220 & 220 & 212 & 217 \\
2 & 237 & 207 & 192 & 212 \\
3 & 220 & 220 & 212 & 217 \\
4 & 220 & 228 & 220 & 223 \\
5 & 220 & 220 & 212 & 217 \\
6 & 220 & 228 & 220 & 220 \\
7 & 228 & 228 & 218 & 225 \\
\hline
\end{tabular}


The IJICS (International Journal of Informatics and Computer Science) Vol 4 No 1, March 2020
ISSN 2548-8384 (online) ISSN 2548-8449 (print)

Page $5-11$

DOI 10.30865/ijics.v4i1.1982

\begin{tabular}{ccccc}
\hline Pixel & R & G & B & $\begin{array}{c}\text { Grey } \\
\text { Level }\end{array}$ \\
\hline 8 & 220 & 228 & 220 & 223 \\
9 & 228 & 230 & 228 & 229 \\
10 & 212 & 220 & 212 & 215 \\
11 & 220 & 220 & 212 & 217 \\
12 & 220 & 220 & 212 & 217 \\
13 & 212 & 212 & 196 & 207 \\
14 & 220 & 220 & 212 & 217 \\
15 & 204 & 204 & 188 & 199 \\
16 & 152 & 157 & 152 & 154 \\
17 & 190 & 187 & 190 & 189 \\
18 & 179 & 181 & 168 & 176 \\
19 & 187 & 202 & 197 & 195 \\
20 & 187 & 202 & 197 & 195 \\
21 & 204 & 204 & 188 & 199 \\
22 & 212 & 220 & 212 & 215 \\
23 & 212 & 212 & 204 & 209 \\
24 & 221 & 212 & 212 & 215 \\
\hline
\end{tabular}

The grey level values in Table 2. are converted into the following matrix form:

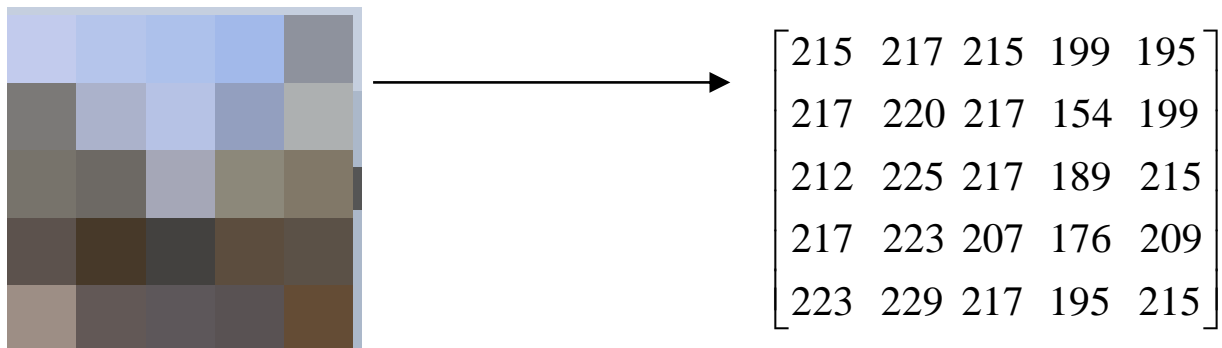

Figure 2. Input Image Matrix

The process of sharpening 3D images is a processing of the image to find the grayscale level limit of the pixels in an image. There are many approaches taken to the problem. In this study, an approach is made to the problem of detection with greylevel transformation.

The steps are as follows :

1. Convolute the image using the Laplace operator.

Steps I : Place the kernel in the upper left corner, then calculate the pixel value at position $(0.0)$ of the kernel

\begin{tabular}{|c|c|c|c|c|c|c|c|c|c|}
\hline 215 & 217 & 215 & 199 & 195 & $*$ & $*$ & $*$ & & \\
\hline 217 & 220 & 217 & 154 & 199 & * & -2 & $*$ & & $*$ \\
\hline 212 & 225 & 217 & 189 & 215 & $*$ & $*$ & $*$ & & \\
\hline 217 & 223 & 207 & 176 & 209 & $*$ & $*$ & $*$ & & \\
\hline 223 & 229 & 217 & 195 & 215 & * & $*$ & $*$ & 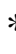 & \\
\hline
\end{tabular}

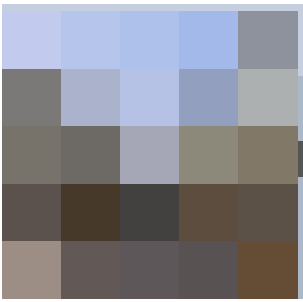

Convolution multiplication process $=-2$; This value is calculated in the following way:

$(0 \times 215)+(-1 \times 217)+(0 \times 215)+(-1 \times 217)+(4 \times 220)+(-1 \times 217)+(0 \times 212)+(-1 \times 225)+(0 \times 217)=-2$

Steps II : Move the kernel one pixel to the right, then calculate the pixel value at position (0.0) of the kernel

$\left[\begin{array}{lllll}215 & 217 & 215 & 199 & 195 \\ 217 & 220 & 217 & 154 & 199 \\ 212 & 225 & 217 & 189 & 215 \\ 217 & 223 & 207 & 176 & 209 \\ 223 & 229 & 217 & 195 & 215\end{array}\right] \longrightarrow\left[\begin{array}{ccccc}* & * & * & * & * \\ * & -2 & 6 & * & * \\ * & * & * & * & * \\ * & * & * & * & * \\ * & * & * & * & *\end{array}\right]$

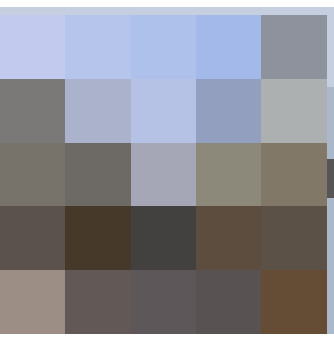


Convolution multiplication process $=6$; This value is calculated in the following way:

$(0 \times 217)+(-1 \times 215)+(0 \times 199)+(-1 \times 220)+(4 \times 217)+(1 \times 154)+(0 \times 225)+(-1 \times 217)+(0 \times 189)=6$

Perform the steps above to the last step as below. Next slide the kernel one pixel down, then start again to convolution from the left side of the image. Then calculate the pixel value at position $(0.0)$ of the kernel

$$
\left[\begin{array}{ccccc}
215 & 217 & 215 & 199 & 195 \\
217 & 220 & 217 & 154 & 199 \\
212 & 225 & 217 & 189 & 215 \\
217 & 223 & 207 & 176 & 209 \\
223 & 229 & 217 & 195 & 215
\end{array}\right]\left[\begin{array}{ccccc}
* & * & * & * & * \\
* & -5 & 24 & -21 & * \\
* & 2 & 4 & -25 & * \\
* & -18 & 14 & -8 & * \\
* & * & * & * & *
\end{array}\right]
$$

Convolution is ignored because the pixels at the bottom corner are hanging, so the bottom-corner pixels, the value remains the same as the original image and become a destination image. Output image is an image that has a color intensity ranging from 0 and 1 (binary image) which is the result of the convolution of the 3D image sharpening process. Output images that have a maximum image size of 256x256 pixels with input images that have the same sizes and formats are also the same which are only done for images of the same type, namely bitmap images (* bmp, * jpeg) to bitmap images (* bmp, * jpeg). To get better image results.

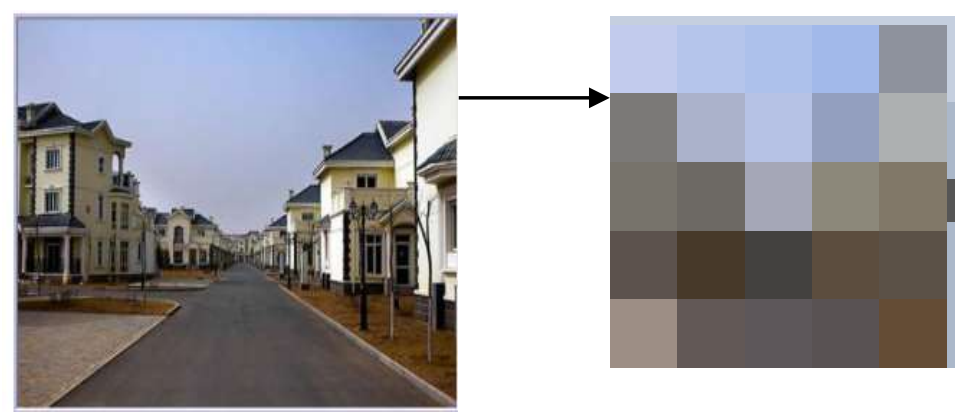

Figure 3. Input Image 317 x 236 pixels

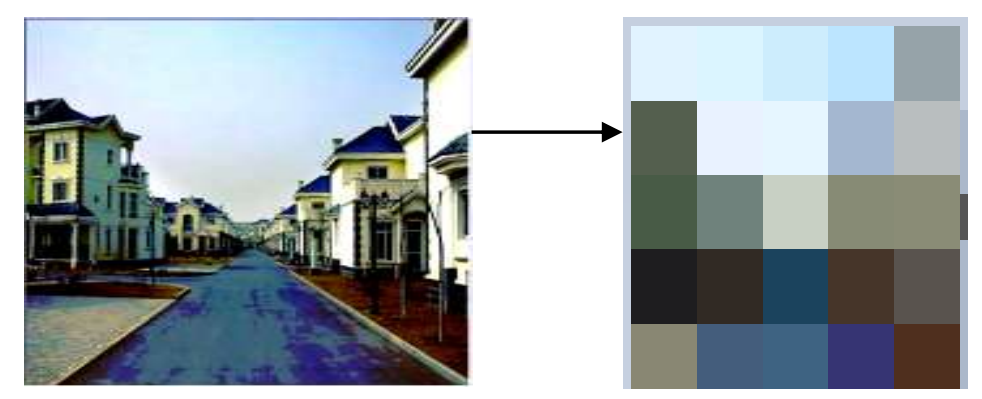

Figure 4. Output Image 317 x 236 pixels

\section{IMPLEMENTATION}

Implementation is not only an activity, but an activity that is planned and carried out seriously by referring to certain norms to achieve the objectives of the activity. Therefore, the implementation does not stand alone but is influenced by the next object. The implementation of this program system includes hardware requirements specifications and software specifications. This system can run smoothly without being separated from clear software to support hardware and these system requirements cannot be separated for the smooth running of the system.

This program display is a display consisting of Initial Image and Image Averaging Results When the program is run, the application display will look like Figure 5. 
The IJICS (International Journal of Informatics and Computer Science) Vol 4 No 1, March 2020
ISSN 2548-8384 (online) ISSN 2548-8449 (print)

Page $5-11$

DOI 10.30865/ijics.v4i1.1982

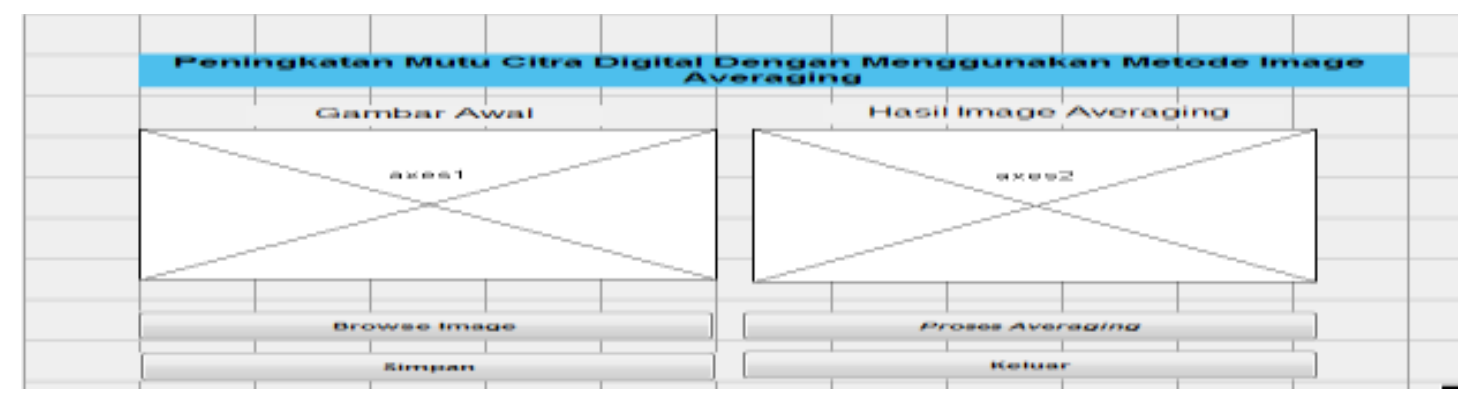

Figure 5. Display Input Averaging Method

The output using the image averaging method is shown in the image below.

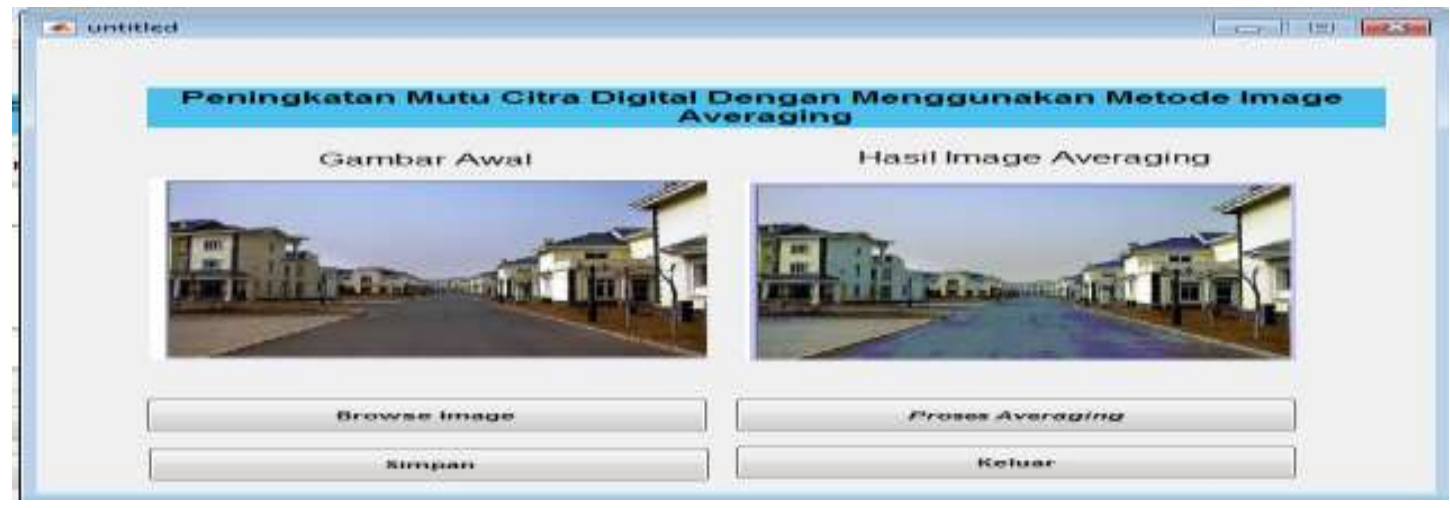

Figure 6. Display Output 7. below:

Based on the trial results of the implementation of the image averaging method and can be seen in Figure

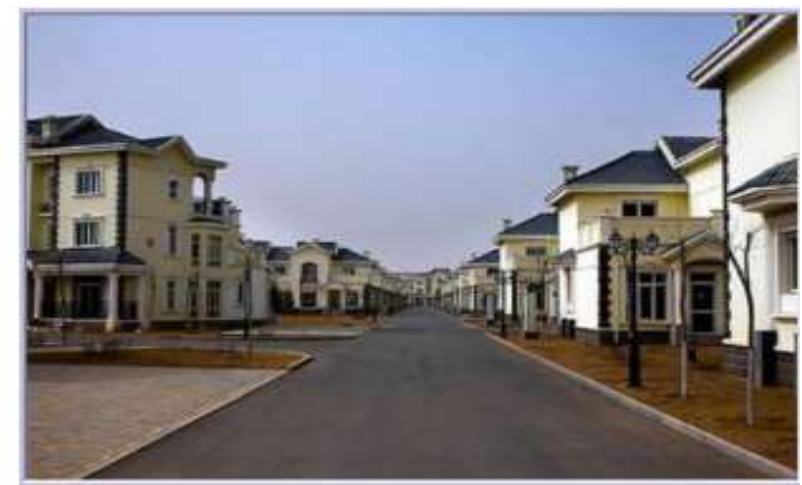

Figure 7. Original Image

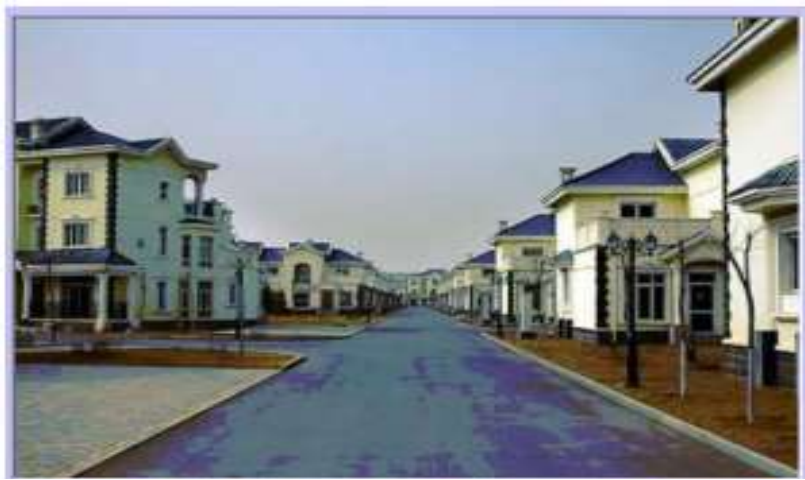

Figure 8. Image Results of the Image Averaging Method 


\section{CONCLUSION}

Based on the discussion and evaluation of the previous chapters and the analysis of the test image file, the following conclusions can be drawn:

1. Improve image quality with the Image Averaging Method which is going to be better.

2. Image improvement that has noise from the arena averaging image method cannot maintain the quality of the resulting image so that the processed image will appear slightly blurry or blurred. After studying the process of improving the quality of digital images it turns out better results are the use of the Image Averaging process.

3. Designing an application to improve the quality of digital images using Matlab 2017

\section{REFERENCES}

[1] P., Karen, 2009 “Image Averaging For Improved Iris Recognition”,

[2] Sutoyoso, 2009, Komponen Komponen Pada Citra, Penerbit Bandung.

[3] http://www, home.unpar.ac.id, tanggal akses 28 Juni 2018.

[4] Munir, 2002. Pengenalan Citra Digital, Penerbit Bandung.

[5] Darma Putra 2010, Pengolahan Citra, Penerbit Andi Yogyakarta.

[6] Hermawati, Fajar Astuti. 2013. "Pengolahan Citra Digital Konsep dan Teori”. Penerbit Andi, Yogyakarta.

[7] Jogiyanto H. M, 2005, Analisis dan Desaign, Penerbit Andi, Yogyakarta. 